\title{
Epigenetic regulator ARID1A and stem cell transcription factor SOX9 in the maintenance of pancreatic ductal cell differentiation state and development of intraductal papillary mucinous neoplasia (IPMN) and pancreatic ductal adenocarcinoma (PDAC)
}

\author{
Naipeng Cui ${ }^{1}$, Jinsong Zhang ${ }^{2}$, Huatian Huang ${ }^{3}$, Lingeng Lu $^{4}$ \\ ${ }^{1}$ Department of Breast Surgery, Affiliated Hospital of Hebei University, Baoding 071000, China; ${ }^{2}$ Department of Pharmacology \& Physiology, Saint \\ Louis University School of Medicine, St. Louis, Missouri, USA; ${ }^{3}$ Department of Imaging Diagnosis, Qian Xi Nan People’s Hospital, Xingyi 652400, \\ China; ${ }^{4}$ Department of Chronic Disease Epidemiology, Yale School of Public Health, School of Medicine, Center for Biomedical Data Science, Yale \\ Cancer Center, Yale University, New Haven, CT, USA \\ Correspondence to: Dr. Lingeng Lu. Department of Chronic Disease Epidemiology, Yale School of Public Health, School of Medicine, Center for \\ Biomedical Data Science, Yale Cancer Center, Yale University, 60 College Street, New Haven, CT 06520-8034, USA. Email: lingeng.lu@yale.edu. \\ Comment on: Kimura Y, Fukuda A, Ogawa S, et al. ARID1A Maintains Differentiation of Pancreatic Ductal Cells and Inhibits Development of \\ Pancreatic Ductal Adenocarcinoma in Mice. Gastroenterology 2018;155:194-209.e2.
}

Submitted Jul 29, 2018. Accepted for publication Jul 31, 2018.

doi: $10.21037 /$ tcr.2018.07.25

View this article at: http://dx.doi.org/10.21037/tcr.2018.07.25

Pancreatic ductal adenocarcinoma (PDAC) is one of the highest mortality malignancies, with average 5 -year survival less than $3 \%$. The etiology of pancreatic cancer has been investigated, and the identified risk factors including such as non-O ABO blood group (1), uncommon hereditary factors of germline mutations in $p 16, B R C A 1$ and $B R C A 2$ (2), obesity, chronic pancreatitis, long-term diabetes mellitus $(3,4)$, Helicobacter pylori colonization (5) and tobacco smoking (6). Somatic mutations of KRAS is a driver mutation with the frequency of over $90 \%$ in invasive $\operatorname{PDAC}(7,8)$, and with the frequency increasing from $36 \%$ to $87 \%$ according to disease progression from PanIN1a to 2-3 preneoplastic lesions $(9,10)$. Besides the KRAS mutations, there exist many other genes with somatic mutations in pancreatic cancer based on The Cancer Genome Atlas (TCGA) pancreatic cancer dataset (Table 1). However, our understanding on the molecular mechanisms of these mutated genes in the development of intraductal papillary mucinous neoplasia (IPMN) and consequently invasive PDAC is still limited $(11,12)$, and the effective therapies against PDAC are lacking (13). In a recent study of Gastroenterology, Kimura and colleagues used available mouse models and clinical samples to investigate the functions of ARID1A (AT rich interactive domain 1A) in the development of IPMN and PDAC (14). Their investigation revealed that conditional Arid1a knockout (KO) mice had dilated pancreatic duct and acceleration of PDAC from IPMN when mutant Kras oncogene was also expressed. Eventually, multilocular cystic neoplasm developed. Interestingly, cystic neoplasm developed in these transgenic mice did not show aggressive cell proliferation, but manifested excessive intraductal mucin. Moreover, cystic neoplasms developed in these mice had the characteristics of IPMN in human, but not that of mucinous cystic neoplasms (MCN). About 20\% (3 out of 15) of these IPMN lesions in the transgenic mice gradually developed into PDAC at 48 weeks of age. They observed decreased expression of Sox9 in Arid1a conditional KO mouse pancreas and marked decreased expression of p21, p53 and $\mathrm{p} 16^{\mathrm{INK} 4_{a}}(C d k n 2 a)$ in mouse IPMN-like cystic neoplasms. They concluded that ARID1A deficiency results in ductal cell dedifferentiation and ductal dilation due to reduced $S O X 9$ expression. This phenotype was rescued by overexpression of SOX9 both in cell culture and in vivo. Their research illuminated an important function of ARID1A which is the maintenance of differentiation of pancreatic ductal cells and the suppression of PDAC development, suggesting that ARID1A may be a target in the chemoprevention of PDAC. Their findings are encouraging and have implications beyond pancreatic cancer. 
ARID1A is an epigenetic regulator involved in chromatin remodeling (15). Its mutations occur at as high frequency as $50 \%$ in a wide range of cancers, and lead to loss of ARD1A function $(16,17)$. The frequency of somatic mutations of ARID1A in human pancreatic cancer is approximately $5 \%$ (Table 1), and the loss of ARIAD1A leads to poor prognosis in the patients (18). Recently, it has been shown that ARID1A promotes mismatch repair (MMR) by recruiting

Table 1 Mutation frequency of the top 72 genes in a TCGA pancreatic cancer data

\begin{tabular}{|c|c|}
\hline Genes & Mutation frequency \\
\hline KRAS & 0.907 \\
\hline TP53 & 0.693 \\
\hline$T T N$ & 0.273 \\
\hline SMAD4 & 0.240 \\
\hline$C D K N 2 A$ & 0.147 \\
\hline MUC16 & 0.133 \\
\hline HMCN1 & 0.080 \\
\hline$L R P 1 B$ & 0.080 \\
\hline$R Y R 1$ & 0.080 \\
\hline OBSCN & 0.080 \\
\hline FAT3 & 0.073 \\
\hline FLG & 0.067 \\
\hline SCN5A & 0.067 \\
\hline FAT2 & 0.067 \\
\hline USH2A & 0.067 \\
\hline ASPM & 0.060 \\
\hline CSMD2 & 0.060 \\
\hline$D M D$ & 0.060 \\
\hline CUBN & 0.060 \\
\hline PLEC & 0.060 \\
\hline DSCAM & 0.060 \\
\hline DSCAML1 & 0.060 \\
\hline DNAH11 & 0.060 \\
\hline GNAS & 0.060 \\
\hline$T N X B$ & 0.060 \\
\hline RYR3 & 0.060 \\
\hline
\end{tabular}

Table 1 (continued)
Table 1 (continued)

\begin{tabular}{|c|c|}
\hline Genes & Mutation frequency \\
\hline SPTA1 & 0.060 \\
\hline GL/3 & 0.060 \\
\hline RNF43 & 0.053 \\
\hline SCN1A & 0.053 \\
\hline CACNA1B & 0.053 \\
\hline FAT4 & 0.053 \\
\hline HERC2 & 0.053 \\
\hline LRP2 & 0.053 \\
\hline CSMD3 & 0.053 \\
\hline ADAMTS16 & 0.053 \\
\hline SYNE1 & 0.053 \\
\hline MYO18B & 0.053 \\
\hline RNF213 & 0.053 \\
\hline RELN & 0.053 \\
\hline PCDH15 & 0.053 \\
\hline ZNF831 & 0.053 \\
\hline ADAMTS12 & 0.053 \\
\hline PRUNE2 & 0.053 \\
\hline SDK1 & 0.053 \\
\hline BTBD11 & 0.047 \\
\hline PCDH9 & 0.047 \\
\hline AKAP6 & 0.047 \\
\hline HECW2 & 0.047 \\
\hline FCGBP & 0.047 \\
\hline RYR2 & 0.047 \\
\hline ATP10A & 0.047 \\
\hline TGFBR2 & 0.047 \\
\hline HECW1 & 0.047 \\
\hline FAM71B & 0.047 \\
\hline RBM12 & 0.047 \\
\hline TMEM132D & 0.047 \\
\hline$A R I D 1 A$ & 0.047 \\
\hline CSMD1 & 0.047 \\
\hline MKI67 & 0.047 \\
\hline
\end{tabular}

Table 1 (continued) 
Table 1 (continued)

\begin{tabular}{lc}
\hline Genes & Mutation frequency \\
\hline PSG6 & 0.047 \\
SSPO & 0.047 \\
LRP1 & 0.047 \\
AMOT & 0.047 \\
ANK3 & 0.047 \\
GPR133 & 0.047 \\
KCNA6 & 0.047 \\
PKD1 & 0.047 \\
HYDIN & 0.047 \\
RREB1 & 0.047 \\
TPO & 0.047 \\
MYLK & 0.047 \\
\hline
\end{tabular}

TCGA, The Cancer Genome Atlas.

MSH2 to chromatin during DNA replication and promotes MMR (19). ARID1A deficiency enhances the efficacy of immune checkpoint blockade (19). In addition, a subunit of the SWI/SNF chromatin remodeling complex (20), ARID1A interacts with a variety of transcription factors and cofactors including p53, HDAC1/2, and SMAD2/3 (16). SOX9 is a stem cell transcription factor with the highmobility-group box class DNA-binding motifs $(21,22)$. Given that stem cell transcription factors in general have the potential of maintaining cells in the undifferentiated state (22), SOX9 mediation of ARID1A function is a novel finding in Kimura's study. But how ARID1A regulates $S O X 9$ expression, and how two factors orchestrate together and the nature of their partners in PDAC, remain to be answered. Many hypotheses can be made. A clear answer to these questions awaits further experimentations in the future.

It is not clear whether SOX9 KO leads to the same phenotype as ARID1A KO-induced one. The data in Kimura's study demonstrated that ARID1A KO in the KRAS mutant background accelerated the development of PDAC through the mTOR pathway. A previous study of this group showed that Brg1 (another SWI/SNF complex component) $\mathrm{KO}$ mice has similar but stronger phenotypes compared to ARID1A KO-induced alterations in pancreatic ducts (23), suggesting that $B R G 1 \mathrm{KO}$ should also have stronger $\mathrm{mTOR}$ pathway activation.

As a chromatin remodeling factor, ARID1A should exert its functions by means of direct regulation of target gene expression. Immunohistochemistry results in Kimura et al.'s study showed that the levels of ARID1A and phosphorylated S6 (a marker of mTOR pathway activation) proteins were decreased in a parallel manner in both human IPMN and PDAC. There is also a positive correlation at the mRNA levels between ARID1A expression and the expression of several key mTOR pathway molecules such as mTOR, PIK3CA, AKT3 and RICTO, suggesting that activation of mTOR pathway is important for tumor progression in ARIAD-low PDAC. Taken together, these results raise the possibility of targeting mTOR pathway in the treatment of human PDAC when ARID1A or BRG1 expression levels are low in the patient tumor samples. Indeed, preclinical studies and clinical trials are in progress (24). It would be interesting to see whether mTOR pathway inhibitors have stronger therapeutic effects against human BRG1-low PDAC than ARID1A-low PDAC. Furthermore, would ARID1A or BRG1 or both be used as liquid biopsy-based biomarkers (for example, the presence of mutated genes in circulating exosomes as early detection of PDAC (25) in the future?

\section{Acknowledgments}

Funding: None.

\section{Footnote}

Provenance and Peer Review: This article was commissioned and reviewed by the Section Editor Xiaoping Yi (Department of Radiology, Xiangya Hospital, Central South University, Changsha, China).

Conflicts of Interest: All authors have completed the ICMJE uniform disclosure form (available at http://dx.doi. org/10.21037/tcr.2018.07.25). The authors have no conflicts of interest to declare.

Ethical Statement: The authors are accountable for all aspects of the work in ensuring that questions related to the accuracy or integrity of any part of the work are appropriately investigated and resolved.

Open Access Statement: This is an Open Access article distributed in accordance with the Creative Commons Attribution-NonCommercial-NoDerivs 4.0 International License (CC BY-NC-ND 4.0), which permits the noncommercial replication and distribution of the article with the strict proviso that no changes or edits are made and the original work is properly cited (including links to both the 
formal publication through the relevant DOI and the license). See: https://creativecommons.org/licenses/by-nc-nd/4.0/.

\section{References}

1. Risch HA, Lu L, Wang J, et al. ABO blood group and risk of pancreatic cancer: a study in Shanghai and metaanalysis. Am J Epidemiol 2013;177:1326-37.

2. Risch HA, McLaughlin JR, Cole DE, et al. Population BRCA1 and BRCA2 mutation frequencies and cancer penetrances: a kin-cohort study in Ontario, Canada. J Natl Cancer Inst 2006;98:1694-706.

3. Risch HA. Diabetes and Pancreatic Cancer: Both Cause and Effect. J Natl Cancer Inst 2018. [Epub ahead of print].

4. Risch HA, Yu H, Lu L, et al. Detectable Symptomatology Preceding the Diagnosis of Pancreatic Cancer and Absolute Risk of Pancreatic Cancer Diagnosis. Am J Epidemiol 2015;182:26-34.

5. Risch HA, Yu H, Lu L, et al. ABO blood group, Helicobacter pylori seropositivity, and risk of pancreatic cancer: a casecontrol study. J Natl Cancer Inst 2010;102:502-5.

6. Risch HA. Pancreatic cancer: Helicobacter pylori colonization, $\mathrm{N}$-nitrosamine exposures, and ABO blood group. Mol Carcinog 2012;51:109-18.

7. Bryant KL, Mancias JD, Kimmelman AC, et al. KRAS: feeding pancreatic cancer proliferation. Trends Biochem Sci 2014;39:91-100.

8. Lennerz JK, Stenzinger A. Allelic ratio of KRAS mutations in pancreatic cancer. Oncologist 2015;20:e8-9.

9. Collins MA, Pasca di Magliano M. Kras as a key oncogene and therapeutic target in pancreatic cancer. Front Physiol 2014;4:407.

10. Lohr M, Kloppel G, Maisonneuve P, et al. Frequency of K-ras mutations in pancreatic intraductal neoplasias associated with pancreatic ductal adenocarcinoma and chronic pancreatitis: a meta-analysis. Neoplasia 2005;7:17-23.

11. Rezaee N, Barbon C, Zaki A, et al. Intraductal papillary mucinous neoplasm (IPMN) with high-grade dysplasia is a risk factor for the subsequent development of pancreatic ductal adenocarcinoma. HPB (Oxford) 2016;18:236-46.

12. Patra KC, Bardeesy N, Mizukami Y. Diversity of Precursor Lesions For Pancreatic Cancer: The Genetics and Biology of Intraductal Papillary Mucinous Neoplasm. Clin Transl Gastroenterol 2017;8:e86.

13. Collisson EA, Sadanandam A, Olson P, et al. Subtypes of pancreatic ductal adenocarcinoma and their differing responses to therapy. Nat Med 2011;17:500-3.

14. Kimura Y, Fukuda A, Ogawa S, et al. ARID1A Maintains
Differentiation of Pancreatic Ductal Cells and Inhibits Development of Pancreatic Ductal Adenocarcinoma in Mice. Gastroenterology 2018;155:194-209.e2.

15. Zhang L, Liu Y, Wang M, et al. EZH2-, CHD4-, and IDH-linked epigenetic perturbation and its association with survival in glioma patients. J Mol Cell Biol 2017;9:477-88.

16. Wu JN, Roberts CW. ARID1A mutations in cancer: another epigenetic tumor suppressor? Cancer Discov 2013;3:35-43.

17. Jones $S$, Wang TL, Shih Ie M, et al. Frequent mutations of chromatin remodeling gene ARID1A in ovarian clear cell carcinoma. Science 2010;330:228-31.

18. Witkiewicz AK, McMillan EA, Balaji U, et al. Whole-exome sequencing of pancreatic cancer defines genetic diversity and therapeutic targets. Nat Commun 2015;6:6744.

19. Shen J, Ju Z, Zhao W, et al. ARID1A deficiency promotes mutability and potentiates therapeutic antitumor immunity unleashed by immune checkpoint blockade. Nat Med 2018;24:556-62.

20. Livshits G, Alonso-Curbelo D, Morris JPt, et al. Arid1a restrains Kras-dependent changes in acinar cell identity. Elife 2018;7:e35216.

21. Kadaja M, Keyes BE, Lin M, et al. SOX9: a stem cell transcriptional regulator of secreted niche signaling factors. Genes Dev 2014;28:328-41.

22. Yang C, Zhao X, Cui N, et al. Cadherins Associate with Distinct Stem Cell-Related Transcription Factors to Coordinate the Maintenance of Stemness in Triple-Negative Breast Cancer. Stem Cells Int 2017;2017:5091541.

23. von Figura G, Fukuda A, Roy N, et al. The chromatin regulator Brg1 suppresses formation of intraductal papillary mucinous neoplasm and pancreatic ductal adenocarcinoma. Nat Cell Biol 2014;16:255-67.

24. Iriana S, Ahmed S, Gong J, et al. Targeting mTOR in Pancreatic Ductal Adenocarcinoma. Front Oncol 2016;6:99.

25. Lu L, Risch HA. Exosomes: potential for early detection in pancreatic cancer. Future Oncol 2016;12:1081-90.

Cite this article as: Cui N, Zhang J, Huang H, Lu L. Epigenetic regulator ARID1A and stem cell transcription factor SOX9 in the maintenance of pancreatic ductal cell differentiation state and development of intraductal papillary mucinous neoplasia (IPMN) and pancreatic ductal adenocarcinoma (PDAC). Transl Cancer Res 2018;7(Suppl 7):S748-S751. doi: 10.21037/tcr.2018.07.25 